\title{
THE PREDICTION OF EXTREME VALUE WIND SPEEDS AND WAVE HEIGHTS FROM SATELLITE DATA
}

\author{
Alicia Takbash, University of Melbourne, atakbash@student.unimelb.edu.au \\ lan Young, University of Melbourne, ian.young@unimelb.edu.au
}

\section{INTRODUCTION}

The prediction of extreme value (e.g. 1 in 100 year) estimates of wind speed and wave height is an essential element of coastal and ocean engineering design. Despite decades of research on the statistics of extreme values, the consistent limitation faced by practitioners is the requirement for a long (20 plus years) dataset at the location of interest. Long term insitu buoy deployments have started to provide useful records in some geographic locations. Long term numerical model hindcasts have also proved useful. However, buoy deployments are seldom at the location of interest and the accuracy of numerical model hindcasts more than 20 years in the past is questionable. This paper will investigate the use of long-term satellite data sets of wind speed and wave height to provide global estimates of extreme values.

\section{SATELLITE DATA SETS}

Oceanographic satellites, measuring wind speed and wave height, have now been in operation for more than 30 years. These systems provide global coverage and for much of this period multiple satellite platforms have been operational. Recently, Young et al (2017) presented a long-term database of calibrated and validated wind speed and wave height data from more than 20 such platforms over this period. This dataset provides the basis for the estimate of extreme values at any location around the globe.

In order to be suitable for extreme value analysis, such a data set must be consistently calibrated and validated over this extended period. In addition, the data must accurately reproduce the tail of the probability distribution function. This paper will examine these elements of satellite data sets obtained from both altimeters and radiometers.

\section{EXTREME VALUE ESTIMATES}

Previous attempts to provide satellite-based extreme value estimates (e.g. Vinoth and Young, 2011) have highlighted limitations including under-sampling of extreme events and the duration of the satellite record. The length and number of satellite platforms included in the present dataset starts to address these issues. Figures (1) and (2) show global values of the 100-year return period significant wave height and wind speed, respectively, obtained from altimeter data using a peaksover-threshold approach.

The presentation will compare such estimates with longterm buoy data and numerical model reanalysis, and examine the limitation of the satellite data. Issues investigated will include: the sampling frequency, spatial aggregation region and choice of extreme-value threshold. Novel techniques, in which data from similar spatial domains is pooled to form a spatial ensemble will also be presented.
The duration of the data set and the consistent manner in which it has been calibrated means that, for the first time, consistent estimates of extreme values can be obtained using a peaks-over-threshold approach. The level of detail in the results exceeds previous global estimates obtained from both model and satellite data sets. As an example, Figure (2) clearly shows the strong belt of high extreme winds in the north equatorial Pacific, associated with the tropical cyclone tracks in this area. This is believed to be the first time that such features have been identified in such global-scale extreme value analyses.

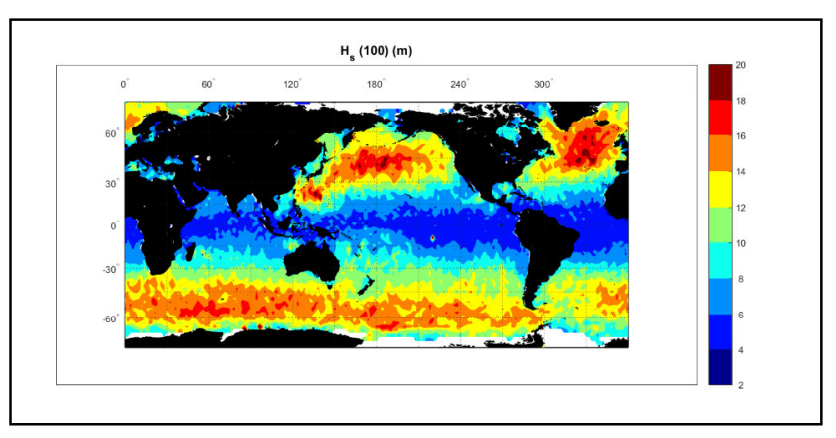

Figure1: Global 100-year return period significant wave height.

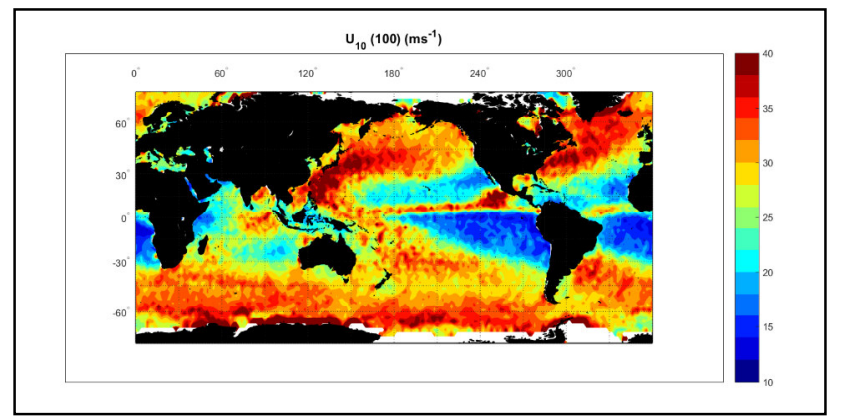

Figure 2: Global 100-year return period wind speed.

\section{REFERENCES}

Vinoth, and Young (2011): Global estimates of extreme wind speed and wave height, J. Climate, 24, 6, 1647-1665.

Young, et al. (2017): Calibration and cross-validation of a global wind and wave database of Altimeter, Radiometer and Scatterometer measurements, J. Atmos. \& Ocean. Tech., 1285-1306. 